
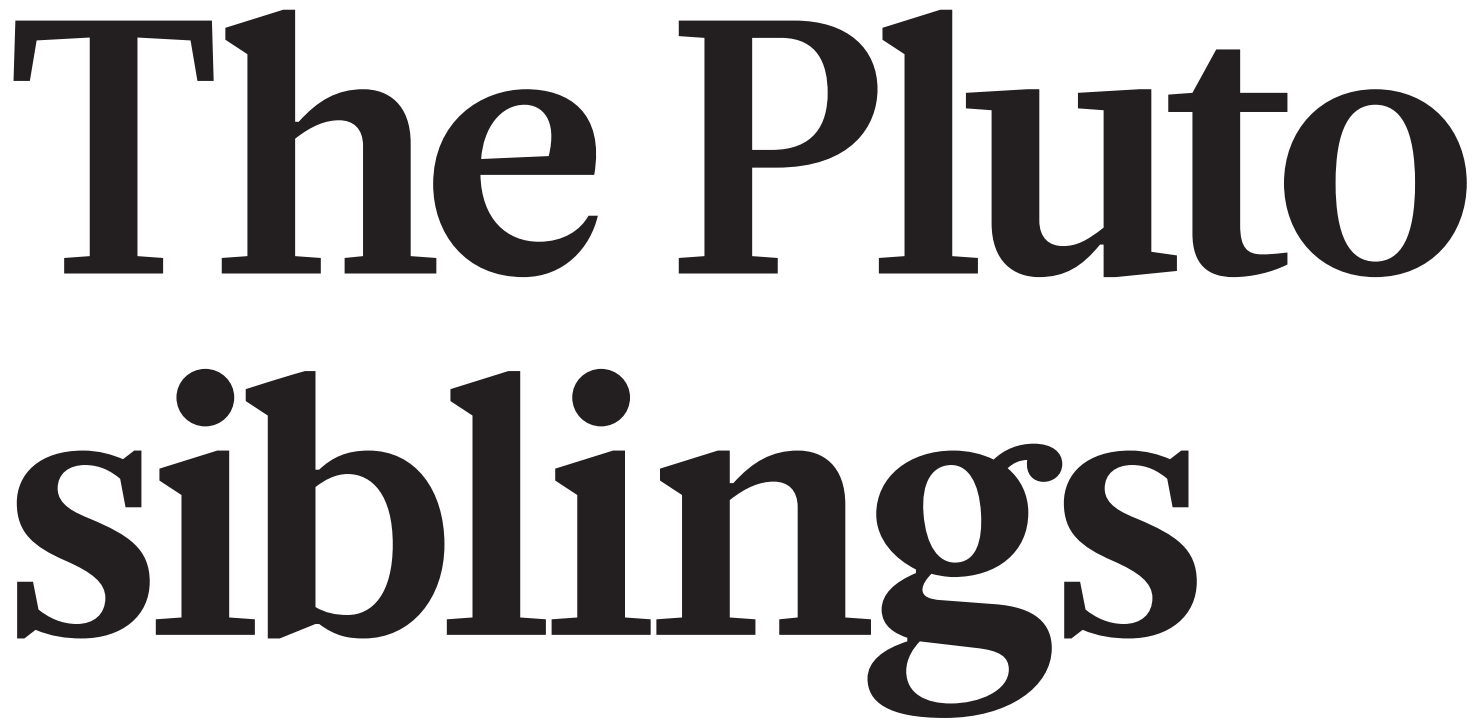

Leslie and Eliot Young have spent their lives studying Pluto. Now they are gearing up for the biggest event of their careers.

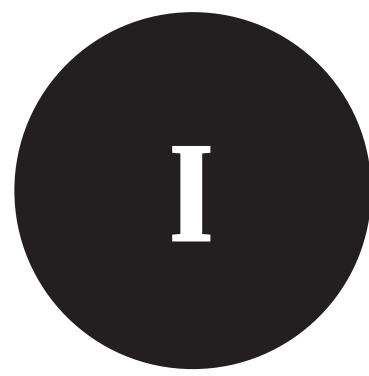

BY ALEXANDRA WITZE

n a spare conference room in Boulder, Colorado, planetary scientists Leslie and Eliot Young quiz a graduate student to prepare him for his upcoming exams. They take their task seriously, interrupting often as he answers questions about Pluto and Neptune's moon Triton.

Leslie makes a technical comment about the light reflecting off those distant worlds. Then, Eliot notes that Pluto and Triton may have started out very similar to one another in the early Solar System before evolving down different paths. "It's a classic case of nature versus nurture," he says. "They are siblings."

So, too, are the Youngs. Eliot and Leslie grew up as the oldest children of an astronautics researcher, and their mutual interests converged on one dwarf planet. "They are the only brother-sister Pluto team in the Solar System," says Alan Stern, a planetary scientist and principal investigator of NASA's New Horizons mission, which has been hurtling towards Pluto for the past nine years.
The Youngs and other Pluto researchers will be gearing up over the next few months as New Horizons finally nears its quarry, 4.8 billion kilometres from Earth. A telescope on the spacecraft has already begun capturing fuzzy pictures of Pluto, which will grow sharper as the probe closes in. And when New Horizons passes within 12,500 kilometres of Pluto on 14 July, it will provide the first close-up look at the world's icy surface, and the best chance yet to answer major questions about the evolution of the outer Solar System (see page 468).

The fly-by will mark a major milestone in both the personal and the professional lives of the Youngs, who occupy adjoining offices at the Southwest Research Institute in Boulder. Over the past quarter of a century, their careers have intersected with Pluto science at key points, from helping to discover the dwarf planet's atmosphere to making some of the first detailed maps of its enigmatic surface. Whatever New Horizons finds this year will build in large part on work done by the siblings.

"We've had some ideas about how Pluto works for decades now," says Eliot. "We'll finally find out if they are right."

\section{FAMILY ORBIT}

When Eliot and Leslie were growing up in Newton, Massachusetts, family life revolved around their father, Larry Young, a legendary researcher at the Massachusetts Institute of Technology (MIT) in Cambridge. Young specializes in the biological effects of weightlessness, and he trained to fly on the space shuttle although he never went into orbit. Eliot, Leslie and their younger brother, Robert, sometimes played poker with visiting astronauts.

Larry Young was also a passionate skier who 


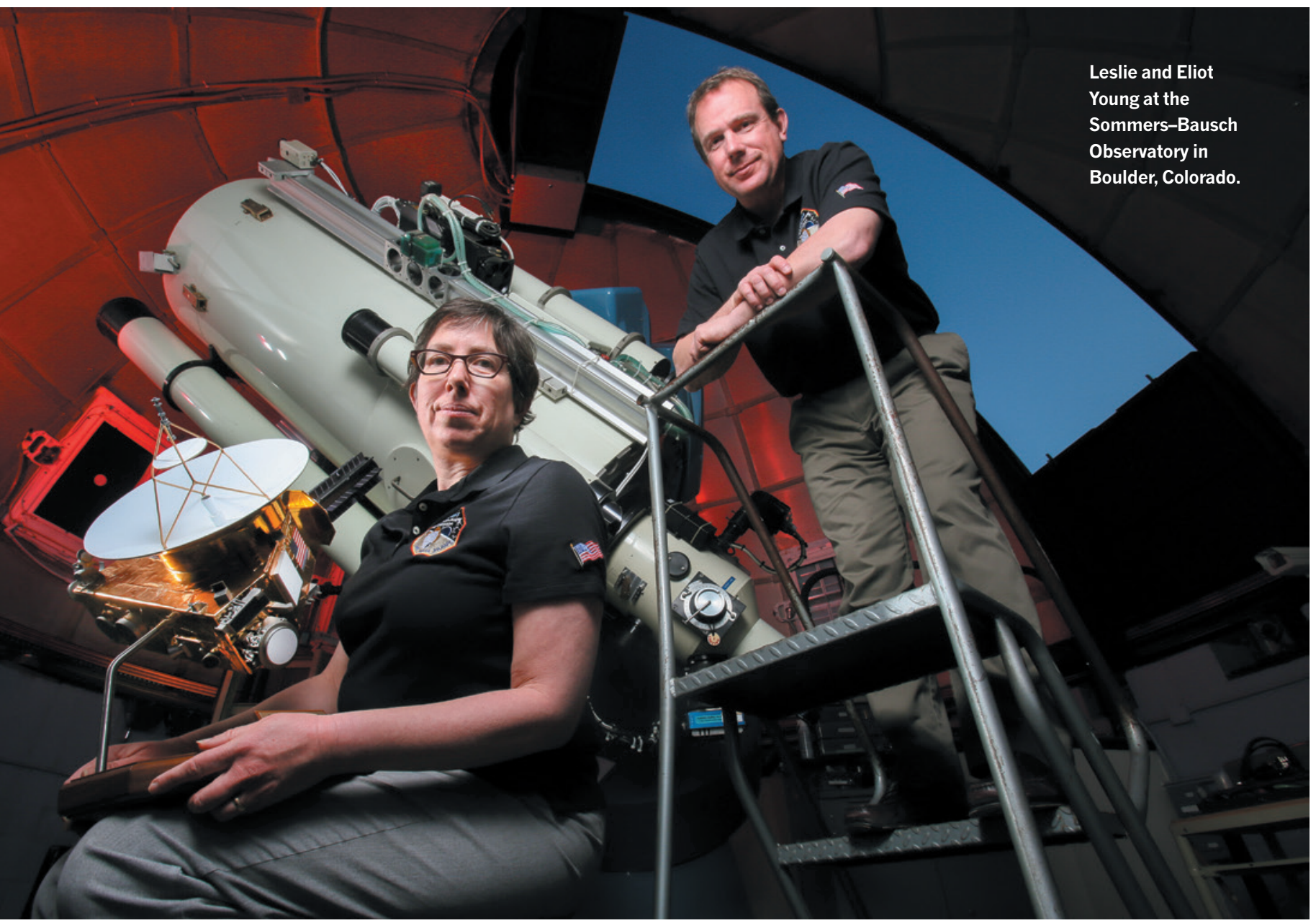

Uy studied skiing injuries. On most winter weekends, his family took a long car trip to New Hampshire that was filled with brain games and chatter about mathematics.

Larry is not surprised that his two oldest children pursued science, but he never imagined them both studying the same dwarf planet in the distant reaches of the Solar System. "I think it's the closest they could get to doing science fiction and still earn a living," he says. (Robert ended up in software development.)

Eliot felt the pull of Pluto first. As a graduate student at MIT in the late 1980s, he worked with Jim Elliot and Ted Dunham, who were building instruments for airborne astronomy missions, including ones to study Pluto. But his sister, three years his junior, quickly followed. One day, she stopped in at his lab to show him a piece of computer coding she had done. Even though she was still an undergraduate at nearby Harvard University, Jim Elliot was impressed enough to offer her a job working on software.

The MIT team specialized in studying distant worlds using stellar occultations - when an object of interest moves between Earth and a background star. By measuring how much the light dims, planetary scientists can determine the size of the blocking

\section{$\rightarrow$ NATURE.COM}

For more on Pluto, see:

nature.com/pluto object. And by noting whether the light dims abruptly or gradually, they can deduce whether that object has an atmosphere. Pluto is so small (about two-thirds the size of Earth's Moon) and far away (between about 30 and 50 times farther from the Sun than Earth is) that astronomers need to use every creative technique they can think of to tease out information.

\section{SKYWATCH}

One night in June 1988, several members of the MIT group took off from Honolulu, Hawaii, in the Kuiper Airborne Observatory, a telescopecarrying plane that flew above the obscuring effects of Earth's atmosphere. Astronomers at the time suspected that Pluto had an atmosphere, but no one had ever spotted it.

Leslie Young was not yet a graduate student, but she was on the plane to help with the measurements. She distinctly remembers the excitement as the star's light dimmed gradually, and Pluto's long-sought atmosphere was revealed ${ }^{1}$. The discovery, supported by ground-based measurements of the same occultation, made front-page headlines. When her brother Robert asked how it felt to have rewritten the textbooks, "I told him it felt pretty good," she says.

Pluto remained a fuzzy dot on a map of the outer Solar System, even as other distant planets were coming into focus. NASA's Voyager 2 spacecraft had visited Uranus in 1986, and three years later it swept past Neptune but did not go near Pluto. Researchers knew little about that world, other than that its surface seemed to be mostly ice, rather than rock, and it was accompanied by a moon, Charon, which was half the size of the dwarf planet itself. (Pluto was demoted from planet status in 2006.)

Helped by her keen coding skills, Leslie went on to make a series of major discoveries as part of the MIT team, including spotting methane in Pluto's atmosphere ${ }^{2}$ and nitrogen ice on its surface 3 . "If somebody asks me what's my favourite colour," she says, "I say 2.15 microns" - the wavelength of the light absorbed by the frozen nitrogen on Pluto's surface.

In the years that followed, Leslie developed computer models to describe how the surface and atmosphere of Pluto interact. Because the orbit of the dwarf planet is extremely stretched out in an elongated ellipse, the amount of sunlight reaching its surface changes markedly throughout the Pluto year, which lasts 248 Earth years. When Pluto's orbit carries it closer to the Sun, methane, nitrogen and other ices on the surface sublimate and form a tenuous atmosphere, roughly one millionth the thickness of Earth's. Some researchers argue that as Pluto gets farther away from the Sun in the coming years, the gases in the atmosphere 
will refreeze and drop to the surface, although Leslie's latest models suggest that the atmosphere never completely disappears ${ }^{4}$.

Occultation studies ${ }^{5,6}$ indicate that the density of Pluto's atmosphere doubled between 1988 and 2002 and has stayed pretty much constant since then. So one of New Horizons' major goals at Pluto is to unravel the icy interplay between the surface and the atmosphere.

\section{FACE OF PLUTO}

The big brother who got Leslie into Pluto has made his own mark. During and after his graduate studies, Eliot worked to map the face of Pluto by taking advantage of a geometric coincidence. Between 1985 and 1990, the orbital planes of Pluto and Charon tilted such that the two worlds regularly passed in front of one another as seen from Earth, allowing astronomers to watch a series of mutual eclipses. By measuring how Pluto's face dimmed as sections of it disappeared from view, researchers could work out which areas were dark and which were light - a property called albedo. Eliot was one of several scientists piecing together these mosaics to produce maps of the dwarf planet's surface ${ }^{7}$.

The maps were far from perfect: "The resolution is like somebody with a strong glasses prescription getting drunk and going to look at the Moon," says Eliot. But they provided some of the first real knowledge about what Pluto might look like. "It was foundational information that got people excited about Pluto," says Marc Buie, a Pluto astronomer now at the Southwest Research Institute. He competed with Eliot to generate the Pluto maps, and gives him credit for inventiveness. "He came up with some ways of tackling the data that I never would have thought of in a million years," says Buie.

Since then, the Hubble Space Telescope has managed to make sharper images of Pluto's surface. By around May this year, New Horizons will be close enough to Pluto to capture images better than Hubble's, and the dwarf planet will finally begin to come into focus. In the highest-resolution pictures, scientists should be able to pick out details as small as the lakes in New York City's Central Park.

Eliot is perhaps best known for his mapping work, but says that his most useful contribution to Pluto science is a method for modelling occultation light curves. He is happiest at the interface between technology and space science, especially if a healthy dose of hardware is involved. "I may still be an engineer at heart," he says. Dunham, now at Lowell Observatory in Flagstaff, Arizona, remembers Eliot building his own computers and housing them in cardboard boxes while in graduate school.

In recent years, Eliot has spent less time on Pluto and more on pushing technical boundaries in another frontier of Solar System science - sending balloons above Earth's atmosphere to make planetary observations. His propensity for technical tinkering has served him in his favourite hobby, too. He developed a new timing system for races at a ski resort near Boulder, where he coaches a team.

Eliot and Leslie's mother, Jody Williams, is not surprised that the siblings have ended up working closely together. During their childhood trips to New Hampshire, where they had no television or other distractions, Eliot and

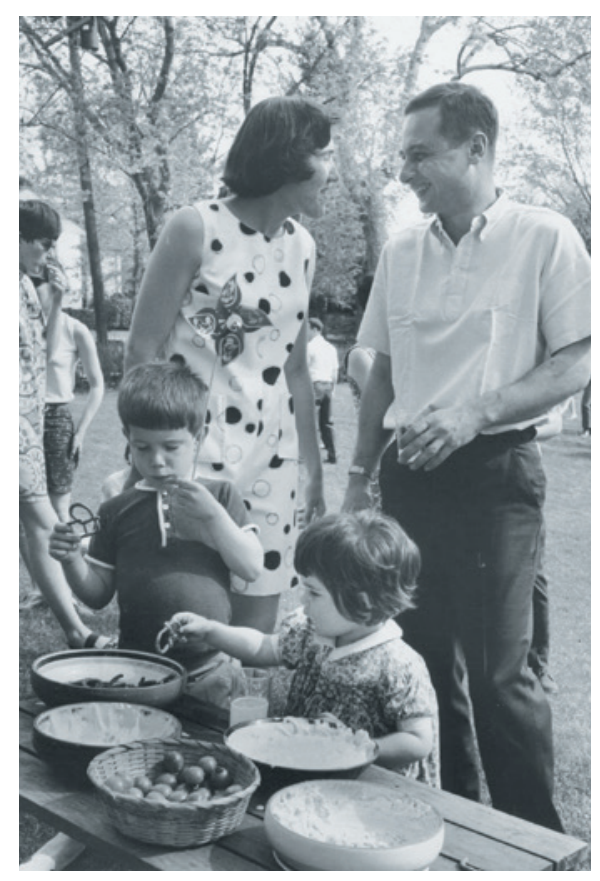

Eliot and Leslie with their parents in 1967.

Leslie would play for hours, building small towns and fantasy worlds with shared rules. Now, Williams says, "every time Eliot runs into a problem, he calls Leslie, and she never lets him down".

Today, Eliot retains a measure of his bigbrother status: he is the gregarious one who often speaks for both of them and is known more widely among planetary astronomers. Leslie, more reserved, sometimes gets noticed initially because she is his sibling. "They learn I'm his sister and they figure I'm worth listening to," she says.

Yet the siblings clearly revel in their close relationship. Both usually work some mention of each other into professional discussions within minutes, and they constantly ricochet ideas between each other's offices. "They know each other better than any of us know either of them," says Stern.

\section{FLY-BY FRENZY}

As Pluto scientists approach peak excitement this year, Eliot will be helping to coordinate a cadre of amateur astronomers across the Southern Hemisphere who will try to capture a major occultation as Pluto passes in front of a particularly bright star on 29 June. It is the last of these events before the New Horizons fly-by, and a crucial data point in the series of occultation studies dating back to the mid1980 s - the only long-term measurements of how Pluto's atmosphere has changed.

Leslie will move to mission control at the Johns Hopkins University Applied Physics Laboratory in Laurel, Maryland, to prepare for intense data gathering. She is a deputy project scientist for New Horizons and the chief architect of the details of the fly-by, a job that involves a steady diet of teleconferences and spreadsheets to coordinate what observation will be made by what instrument at what time. The mission team has carried out several dry runs of the entire encounter, trying to anticipate every possibility in what will be an actionpacked few days leading up to and after the closest approach. "I've been working for the future for 15 years, and the pay-off is coming this summer," says Leslie.

Among other things, she has developed alternative trajectories for the spacecraft to divert to if it seems to be heading for a particularly dusty patch of space. With the spacecraft moving at nearly 50,000 kilometres per hour, collisions with dust particles could endanger it or damage instruments.

Cathy Olkin at the Southwest Research Institute, who was part of Jim Elliot's MIT group a few years after Leslie and is another New Horizon's deputy project scientist, says that observing occultations was good training for making high-stress, time-crucial measurements. She and Leslie have chased Pluto's shadow across islands in the Pacific and during snowstorms in New Zealand. "We know the value of telescope time and being prepared and having thought out what we're going to do at each step in time," says Olkin. "We know we have to get the data."

Back in her office, Leslie Young takes down her 1978 edition of David Halliday and Robert Resnick's Fundamentals of Physics textbook. She opens it to the back, to the reference table listing characteristics of Solar System objects. For Mercury, Venus, Earth and the rest of the planets, the table looks reassuringly full. For Pluto, the data column is incomplete.

One-third of the entries are question marks. Many of the rest are flat-out wrong. "Moons: none," it reads. (Charon had yet to be discovered.) "Atmosphere: none." (Ditto.)

Leslie runs her finger down the column, ticking off the Pluto discoveries that she and her big brother have been involved in. Atmosphere, radius, albedo, surface temperature - all key to understanding this curious little world. In July, she and Eliot hope to help fill in many of the remaining question marks. And maybe even add some new ones.

Alexandra Witze is a correspondent for Nature based in Boulder, Colorado.

1. Elliot, J. L. et al. Icarus 77, 148-170 (1989).

2. Young, L. A. et al. Icarus 127, 258-262 (1997).

3. Owen, T. C. et al. Science 261, 745-748 (1993)

4. Olkin, C. B. et al. Icarus 246, 220-225 (2015).

5. Elliot, J. L. et al. Nature 424, 165-168 (2003)

6. Sicardy, B. et al. Nature 424, 168-170 (2003).

7. Young, E. F. \& Binzel, R. P. Icarus 102, 134-149 (1993). 